\title{
On Estimating the Surface Wind Stress over the Sea
}

\author{
LARRY MAHRT \\ NorthWest Research Associates, Corvallis, Oregon \\ SCOTT MiLLER \\ Atmospheric Sciences Research Center, University at Albany, State University of New York, Albany, New York
}

TIHOMIR HRISTOV

Department of Mechanical Engineering, The Johns Hopkins University, Baltimore, Maryland

JAMES EDSON

Applied Ocean Physics and Engineering Department, Woods Hole Oceanographic Institution, Woods Hole, Massachusetts

(Manuscript received 4 January 2018, in final form 13 April 2018)

\begin{abstract}
Our study analyzes measurements primarily from two Floating Instrument Platform (FLIP) field programs and from the Air-Sea Interaction Tower (ASIT) site to examine the relationship between the wind and sea surface stress for contrasting conditions. The direct relationship of the surface momentum flux to $U^{2}$ is found to be better posed than the relationship between $u *$ and $U$, where $U$ is the wind speed and $u *$ is the friction velocity. Our datasets indicate that the stress magnitude often decreases significantly with height near the surface due to thin marine boundary layers and/or enhanced stress divergence close to the sea surface. Our study attempts to correct the surface stress estimated from traditional observational levels by using multiple observational levels near the surface and extrapolating to the surface. The effect of stability on the surface stress appears to be generally smaller than errors due to the stress divergence. Definite conclusions require more extensive measurements close to the sea surface.
\end{abstract}

\section{Introduction}

Foreman and Emeis (2010), Andreas et al. (2012), Edson et al. (2013), Vickers et al. (2015), Sun and French (2016), Zou et al. (2017), and others have found that the friction velocity $u *$ over the sea can generally be estimated as a function of wind speed $U$ alone without significant loss in parameterization skill. These formulations avoid difficulties with evaluation of similarity theory that include shared variables (self-correlation) and might better accommodate the incorporation of wave effects and other physics that are not included in similarity theory. Stability is expected to influence the relationship between the wind and stress with strong temperature advection over the sea. Oost et al. (2002) found that wave state can also significantly influence the dependence of $u_{*}$ on the wind speed $U$.

\footnotetext{
Corresponding author: Larry Mahrt, mahrt@nwra.com
}

The averaged value of the observed $u *$ remains significant for vanishing vector-averaged wind, which corresponds to a very large drag coefficient. Models of $u_{*}=f(U)$ circumvent this difficulty by imposing vanishing $u *$ with vanishing wind speed. Edson et al. (2013) avoided this issue by bin-averaging the observed alongwind momentum flux and then computing $u *$ (see their Fig. 10). Rieder and Smith (1998) directly related the along-wind momentum flux to $U^{2}$.

We also recognize that the observational estimates of surface stress over the sea might be contaminated by significant errors. For example, the stress can decrease significantly with height near the sea surface (Miller 1998; Mahrt et al. 2001; Ström and Tjernström 2004; Fairall et al. 2006; Smedman et al. 2009). Miller (1998) conducted a detailed study of the momentum flux divergence (convergence) in the lowest $20 \mathrm{~m}$ and its dependence on wind speed and wave state. He concluded that the surface stress can be seriously underestimated 
using conventional observational levels such as $10 \mathrm{~m}$ or higher. He also found that the stress divergence was relatively larger during periods of increasing wind waves and periods of high winds and waves. The influence of wave state on the stress divergence might be inferred from the significant influence of the wave state on the near-surface stress vector. Rieder et al. (1994), Grachev and Fairall (2001), Grachev et al. (2003), and others have found that swell can significantly alter the direction of the surface stress.

The large stress divergence near the surface might be due to thin boundary layers over the sea. The stress profile can also be distorted by momentum advection, particularly in the heterogeneous coastal zone (Fairall et al. 2006). Height dependence of the horizontal pressure gradient associated with horizontal variation of air temperature can also augment the flux divergence. Rieder and Smith (1998) noted the potential impact of nonstationarity of the wind on the surface stress. All of these influences can modify the momentum flux divergence. At the same time, the measured stresses can be influenced by errors due to flow distortion and platform motion (Edson et al. 1998; Miller et al. 2008), which in turn can contaminate the measured stress divergence.

Our study attempts to estimate the surface stress by downward extrapolating flux observations from multiple flux levels near the sea surface. The goal is not to develop a new parameterization but rather to examine the vertical structure of the momentum flux near the surface and examine the impact of the analysis method. Our study analyzes a number of different datasets to provide a preliminary assessment of generality.

\section{Measurements}

\section{a. ASIT, CBLAST Low-Wind}

We analyze data from the Air-Sea Interaction Tower (ASIT) collected during the CBLAST Low-Wind experiment in late summer of 2003 (Edson et al. 2007). The offshore tower is located $3 \mathrm{~km}$ south of Martha's Vineyard in $15 \mathrm{~m}$ of water. We analyze $20-\mathrm{Hz}$ turbulence measurements from CSAT3 sonic anemometers at approximately 6,8 , and $12 \mathrm{~m}$ above the mean sea surface for the first part of the field program and approximately 4,6 , and $10 \mathrm{~m}$ for the second part of the field program. Evaluation of the relationship between the stress and the wind speed uses the 6-m measurements. In addition to the nominal quality control that eliminated obviously impossible values, data with wind direction between $0^{\circ}$ and $120^{\circ}$ were eliminated to reduce the effects of flow distortion by the tower.

\section{b. RED}

Our analysis also includes measurements from two field programs using the Floating Instrument Platform (FLIP). The Rough Evaporation Duct (RED) Experiment (Anderson et al. 2004; Högström et al. 2013) collected observations from 2 to 15 September 2001 in the trade-wind regime approximately $10 \mathrm{~km}$ upwind from the coast of Oahu, Hawaii. This short dataset is limited primarily to weakly unstable conditions with moderate winds speeds. Our study analyzes $50-\mathrm{Hz}$ measurements of the velocity components from Campbell CSAT3 sonic anemometers deployed at 5.1, 6.9, 9.9, and $13.8 \mathrm{~m}$. We use $10-\mathrm{min}$-averaged values of the fluxes. Our postprocessing is described in Mahrt and Hristov (2017).

\section{c. $M B L$}

The Marine Boundary Layer (MBL) Experiment was conducted in 1995 approximately $50 \mathrm{~km}$ offshore from Monterey, California (Rieder and Smith 1998; Hristov et al. 2003). Four Gill sonic anemometers were deployed at 3.9, 8.7, 13.8, and $18.2 \mathrm{~m}$. The datasets were filtered to minimize measurement uncertainties due to platform flow distortion. For MBL, we focus on a 6-day period when the wind and waves were approximately aligned with a long fetch toward the North Pacific.

\section{d. Higher wind speeds}

For higher wind speeds, we also analyze measurements from the Climate Variability and Predictability Mode Water Dynamic Experiment (CLIMODE; Marshall et al. 2009; Edson et al. 2013), the drifting AirSea Interaction Spar (ASIS) (Edson et al. 2013), and the University of New Hampshire buoy (UNH; http://www. opal.sr.unh.edu/data/airsea_flux.shtml). The buoy measurements were at approximately $4 \mathrm{~m}$ above the instantaneous sea surface. The anemometers are corrected for motion contamination as described by Edson et al. (1998) and Flügge et al. (2016).

\section{e. Averaging}

The flow is partitioned as

$$
\phi=\phi^{\prime}+\bar{\phi}
$$

where $\phi$ is one of the velocity components, $\bar{\phi}$ is the average over an averaging window (see below), and $\phi^{\prime}$ is the deviation from such an average. The wind speed is computed from the wind components averaged over the averaging windows

$$
U \equiv \sqrt{\bar{u}^{2}+\bar{v}^{2}}
$$


The friction velocity is computed as

$$
u_{*} \equiv\left({\overline{w^{\prime} u^{\prime}}}^{2}+{\overline{w^{\prime} v^{\prime}}}^{2}\right)^{0.25} \text {. }
$$

where $u^{\prime}, v^{\prime}$, and $w^{\prime}$ are fluctuating velocity components and $\overline{w^{\prime} u^{\prime}}$ and $\overline{w^{\prime} v^{\prime}}$ are the corresponding momentum fluxes.

Unless otherwise noted, the $x$ coordinate is rotated into the direction of the wind vector for each averaging window. We analyze primarily the resulting along-wind momentum flux $\overline{w^{\prime} u^{\prime}}$. The crosswind momentum flux can be nonnegligible sometimes attributed to temperature advection and stability (Geernaert et al. 1993) or waveinduced turning of the stress vector (Geernaert et al. 1993; Rieder et al. 1994; Grachev and Fairall 2001). In our datasets, the experiment-averaged crosswind stress is generally much smaller than the along-wind stress. As one exception, the experiment-averaged crosswind stress appears to be potentially important in the MBL field program, although the crosswind stress did not significantly alter the vertical divergence of the total stress.

For the RED and MBL measurements, turbulent fluctuations are defined as deviations from 10-min averages after linearly detrending each 10 -min window. Because the ASIT data include significantly stable cases, a smaller averaging window of $1 \mathrm{~min}$ is used to reduce contamination of the computed fluctuations by nonturbulent motions. The choice of a smaller averaging time mainly affected only the most stable conditions. The 1-min averaging may exclude detectable flux for higher winds where transporting eddies become larger and more elongated in the wind direction. However, based on longer averaging times, significant flux loss did not emerge, probably because the wind speeds are generally modest in this dataset.

Averages for individual windows are characterized by large uncertainty. As a result, we composite the window averages for different intervals of some forcing variable such as $U$. Composited variables are symbolized by square brackets such that the composited along-wind momentum flux is written as $\left[\overline{w^{\prime} u^{\prime}}\right]$. Bin averages are accepted only for bins with greater than 20 points for the FLIP fluxes based on 10-min averages and 200 points for the shorter 1-min averages for the ASIT measurements.

Among the different datasets, the standard error of $\left[\overline{w^{\prime} u^{\prime}}\right]$ can exceed $30 \%$ of the magnitude of $\left[\overline{w^{\prime} u^{\prime}}\right]$ for the bin with the lowest wind speeds (less than few meters per second depending on the site). The standard error relative to the magnitude of $\left[\overline{w^{\prime} u^{\prime}}\right]$ decreases rapidly with increasing $U$ to less than $1 \%$ of the flux magnitude for large $U$. However, the standard error can significantly
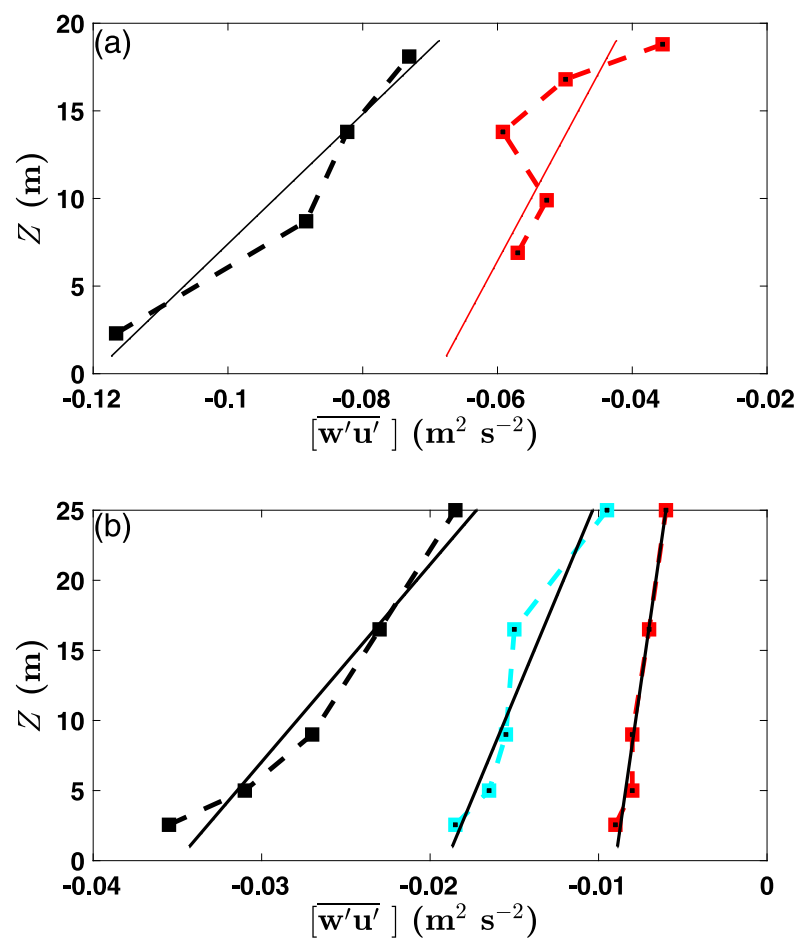

FIG. 1. (a) The along-wind momentum flux $\left[\overline{w^{\prime} u^{\prime}}\right]$ for the RED (red) and MBL (black) measurements. Thin lines are the regression fits [Eq. (4), Table 1]. (b) The profile of the along-wind momentum flux $\left[\overline{w^{\prime} u^{\prime}}\right]$ for Östergarnsholm measurements from Smedman et al. (2009) for wind following swell (black), wind across the swell (cyan), and weak flow across the swell (red). Thin lines are the linear regression fits.

underestimate the true sampling error because the samples are not independent, partly due to nonstationarity (Mahrt and Thomas 2016). Because $\left[\overline{w^{\prime} u^{\prime}}\right]$ is not a true ensemble mean, deviations of $\overline{w^{\prime} u^{\prime}}$ from $\left[\overline{w^{\prime} u^{\prime}}\right]$ cannot be formally considered as purely random variations. We use the more vague term "random-like," and we do not make quantitative use of the standard error.

\section{Flux divergence}

The momentum flux varies significantly with height in the measurements analyzed in our study in what would normally be considered the surface layer. This flux divergence may invalidate similarity theory and leads to underestimation of the surface stress using typical observational levels.

\section{a. Stress profile parameters}

The vertical profiles of $\left[\overline{w^{\prime} u^{\prime}}\right]$ are fit using simple linear regression (thin lines in Fig. 1) such that

$$
\left[\overline{w^{\prime} u^{\prime}}\right]=\left[\overline{w^{\prime} u^{\prime}}\right]_{\mathrm{sfc}}+\gamma Z,
$$


TABLE 1. Regression fit of the vertical profile of the momentum flux. Quantity [[V]] is the experiment averaged 10-m wind speed, $\gamma$ $\left(10^{-3} \mathrm{~m} \mathrm{~s}^{-2}\right)$ is the slope of the fitted regression, $\left[\overline{w^{\prime} u^{\prime}}\right]_{\text {sc }}$ is the estimated surface momentum flux, $h_{S}$ is the depth scale [Eq. (5)], and $E$ $(10 \mathrm{~m})$ is the percent underestimation of the surface momentum flux using $10 \mathrm{~m}$ observations. Descriptor $\mathrm{F}$ refers to flow following the swell, C refers to cross swell flow, and CW refers to weak cross swell flow (Fig. 1).

\begin{tabular}{|c|c|c|c|c|c|}
\hline Site & {$[[V]]\left(\mathrm{m} \mathrm{s}^{-1}\right)$} & $\gamma\left(10^{-3} \mathrm{~m} \mathrm{~s}^{-2}\right)$ & {$\left[\overline{w^{\prime} u^{\prime}}\right]_{\mathrm{sfc}}\left(\mathrm{m}^{2} \mathrm{~s}^{-2}\right)$} & $h_{S}(\mathrm{~m})$ & $E(10 \mathrm{~m})$ \\
\hline RED & 7 & 1.4 & -0.068 & 49 & 20 \\
\hline MBL & 7.5 & 2.7 & -0.120 & 44 & 23 \\
\hline LongEZ CBLAST & 5 & 8.5 & -0.020 & 23 & 45 \\
\hline Öster, F & 5.5 & 0.7 & -0.038 & 49 & 20 \\
\hline Öster, C & 4.5 & 0.35 & -0.019 & 54 & 19 \\
\hline Öster, CW & 4 & 0.12 & -0.009 & 75 & 19 \\
\hline
\end{tabular}

where $Z$ is the height above the sea surface. The values of $\gamma$ are reported in Table 1. Parameter $\gamma$ is positive because the downward momentum decreases with height. Parameter $\left[\overline{w^{\prime} u^{\prime}}\right]_{\text {sfc }}$ is the constant determined from the regression analysis. To facilitate interpretation, we define the depth scale of the flux divergence $h_{S}$ as

$$
h_{S} \equiv-\frac{\left[\overline{w^{\prime} u^{\prime}}\right]_{\text {sfc }}}{\gamma}
$$

such that $h_{S}$ is the height where the regression relationship predicts vanishing momentum flux, which might be significantly different from the height where the stress actually (approximately) vanishes. Then

$$
\left[\overline{w^{\prime} u^{\prime}}\right]=\left[\overline{w^{\prime} u^{\prime}}\right]_{\mathrm{sfc}}-\left[\overline{w^{\prime} u_{\mathrm{sfc}}^{\prime}}\right] \frac{Z}{h_{S}}
$$

or

$$
\left[\overline{w^{\prime} u^{\prime}}\right]_{\mathrm{sfc}}=\left[\overline{w^{\prime} u^{\prime}}\right] /\left(1-Z / h_{S}\right)
$$

As $Z / h_{S}$ vanishes, the predicted surface momentum flux approaches the observed momentum flux. Equation (7) becomes poorly posed if $Z$ is not small compared to $h_{S}$ because the estimated surface momentum flux becomes mostly correction. In our measurements, the depth scale $h_{S}$ tends to increase with increasing $U$, although the relationship is typically weak (not shown). Height $h_{S}$ presumably also depends on stability, wave state, and impacts of the actual boundary layer depth. Nonetheless, $h_{S}$ varies between field programs less than $\gamma$ varies.

The downward momentum flux varies significantly within the observational layer at both of the FLIP sites. Noting that the fractional underestimation of the surface momentum flux is $Z / h_{S}$, the underestimation of the surface stress by using the $10-\mathrm{m}$ momentum flux ranges from $18 \%$ to $30 \%$ (Table 1). A simple correction for the estimated surface stress is to augment the measured momentum flux by $2 \% Z$. This rate of decrease with height corresponds to $h_{S}=50 \mathrm{~m}$, which approximates most of the individual datasets (Table 1). Parameter $h_{S}$ for the RED measurements in the trade-wind regime is only about $50 \mathrm{~m}$, even though the depth of the convectively mixed flow (subcloud layer) might be an order of magnitude greater.

We consult two additional composited profiles of the momentum flux available from the literature. The LongEZ observations (Mahrt et al. 2016, their Fig. 3) were taken in offshore flow of warm air over cooler water near the ASIT site and indicate a stable boundary layer of $20-25 \mathrm{~m}$ depth. Within the uncertainties of the observed vertical structure, $h_{S}$ and the boundary layer depth are of comparable magnitude for this thin boundary layer. These measurements suggest that the observation height should be in the lowest couple of meters for a reasonable estimate of the surface stress. The momentum flux profiles at the Östergarnsholm site (Smedman et al. 2009, their Fig. 9) correspond to weaker turbulence but again show roughly linear stress profiles (Fig. 1b) and significant flux divergence even in the lowest $10 \mathrm{~m}$.

The above results (Table 1) imply that the surface layer, where the height variation of the momentum flux can be neglected, is typically only $2-8 \mathrm{~m}$ deep depending on site. Because we have been unable to construct a reliable speed-dependent correction to the surface stress for the current datasets, a constant value of $h_{S}$ is used for each field program to augment the surface stress for use in section 4 . The corrected surface stress values are computed only as plausible estimates.

Even though the stress divergence can be substantial over the lowest 10 , the log wind profile remains a reasonable approximation for the high-resolution profile of cup anemometers in MBL (Fig. 2). The log profile is computed as

$$
U_{10}=U\left(Z_{m}\right)+\left(u_{*} / \kappa\right) \log \frac{10 \mathrm{~m}}{Z_{m}},
$$

where $Z_{m}$ is the measurement height and $u *$ [Eq. (3)] is based on the "corrected" surface stress [Eq. (7)]. 


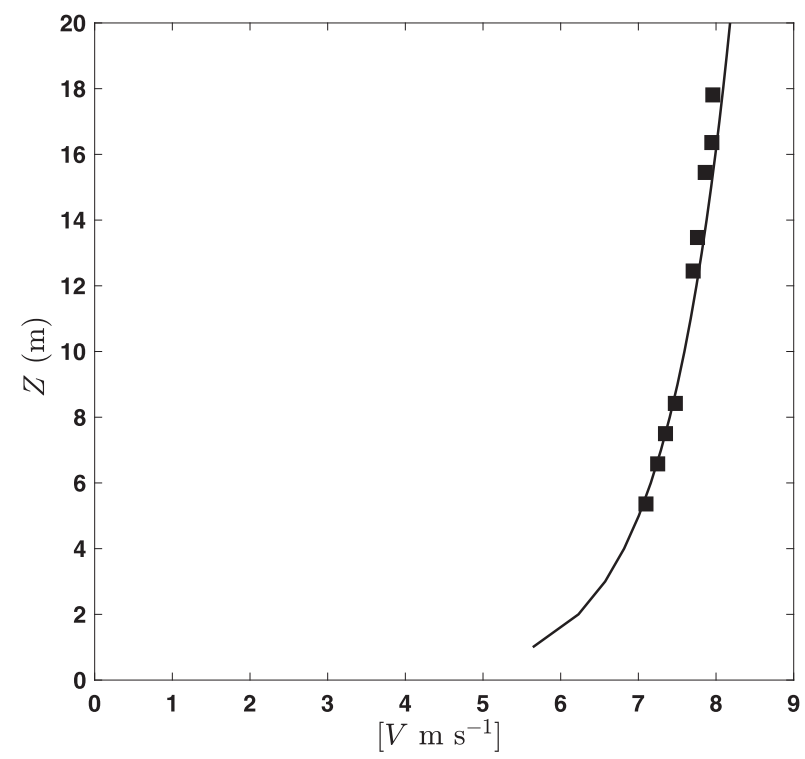

FIG. 2. The log profile (solid line) based on Eq. (8) and the estimated surface stress [Eq. (7)] for MBL, and the averaged speed of the cup anemometers (solid circles).

The wind speed is adjusted to $10 \mathrm{~m}$ using Eq. (8) for comparison between the field programs in sections $4 \mathrm{~b}$ and $4 \mathrm{c}$.

The near-coastal zone is more complex. At the ASIT tower site, the magnitude of the composited downward momentum flux (Fig. 3) tends to increase slowly with height (momentum flux convergence), although the momentum flux divergence is highly variable among individual profiles. The airflow often advects greater turbulent intensity from land located to the north and west of the tower site or possibly greater intensity of turbulence from warmer water to the south of the site (Mahrt et al. 2016). As an apparent result of this advection of turbulence, the magnitude of the momentum flux often increases with height at the ASIT site. Skyllingstad et al. (2005) found a significant increase of the friction velocity $(u *)$ with height up to $100 \mathrm{~m}$ in offshore flow from a rough, warm land surface over a smooth, cooler sea surface. In contrast, thin, stable boundary layers are often observed at the ASIT tower as a result of flow of warm air from land over the cooler water where the downward momentum flux decreases rapidly with height across the thin boundary layer, as in the example provided by Mahrt et al. (2016). Unfortunately, the vertical divergence of the flux for the ASIT measurements appears to be related to wind speed, wind direction, fetch, wave state, and stratification, all of which are correlated to each other. Sorting out the impact of these influences, if possible, is a study in itself. In our study, no corrections are made to the surface stress values for the ASIT measurements.

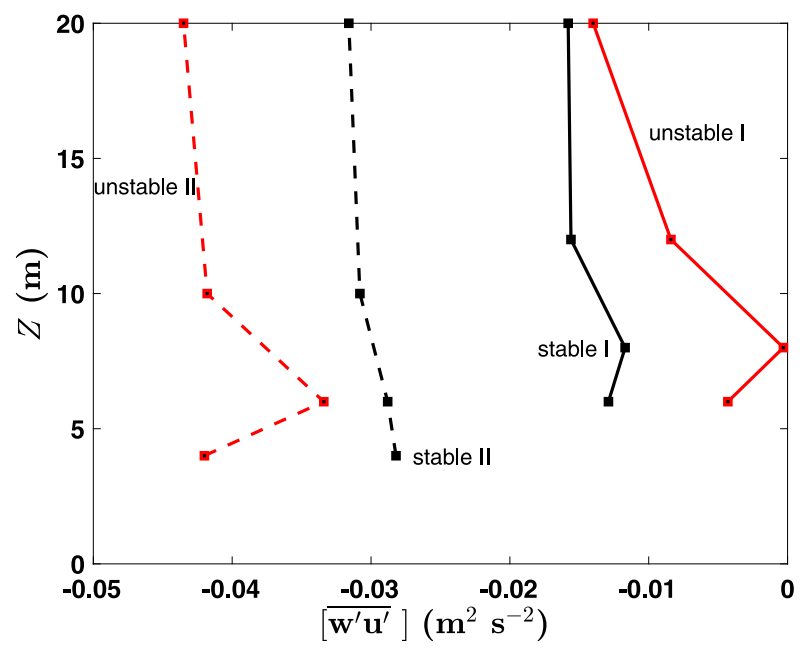

FIG. 3. The composited along-wind momentum flux $\left[\overline{w^{\prime} u^{\prime}}\right]$ for the ASIT tower measurements for the early summer (period I, solid) and the late summer-fall (period II, dashed). Stability is determined from the sign of the heat flux.

\section{b. Unknown cause of the stress divergence}

The cause of the large stress divergence remains generally unknown, although Miller (1998) finds significant enhancement of the relative stress divergence with growing waves and with high wind speeds and high waves. These potential relationships remain under investigation.

The stress divergence must balance the other terms in the equations of motion. We are unable to adequately infer the stress divergence from the equations of motion, but we can use such equations to identify additional needed measurements. Analysis of the full equations of motion leads to numerous scenarios. Here, we consider the simplified case of stationary homogeneous flow where the wind and stress directions are independent of height. Then

$$
0=-\bar{\alpha} \frac{\partial \bar{p}}{\partial x}-\frac{\partial \overline{w^{\prime} u^{\prime}}}{\partial z}
$$

where the Coriolis term $f \bar{v}$ is zero by definition of the coordinate system that is rotated into the wind direction. With this balance, the stress divergence is forced only by the horizontal pressure gradient. The height dependence of the horizontal pressure gradient presumably affects the height dependence of the stress divergence.

Writing Eq. (9) in bulk form, we obtain an estimate of $h_{S}$,

$$
h_{S}=\frac{\overline{w^{\prime} u_{\mathrm{sfc}}^{\prime}}}{\bar{\alpha} \frac{\partial \bar{p}}{\partial x}},
$$


where again $h_{S}$ is the top of the momentum boundary layer where the stress becomes small. The horizontal pressure gradient in Eq. (10) is interpreted as a vertical average. With this relationship, $h_{s}$ decreases linearly with decreasing surface stress such that small surface stress over the sea, compared to over land, leads to small depth of the momentum boundary layer. Estimates of the horizontal pressure gradient are not routinely available and in any event may be sensitive to the horizontal scale of the pressuregradient estimate.

The boundary layer depth is commonly estimated as

$$
h=C u_{*} / f .
$$

Although the constraining influence of the Coriolis parameter on the boundary layer depth in the actual atmosphere has been difficult to isolate, $C$ has been historically estimated to be about 0.25 (Garratt 1994). Based on Eq. (11), the bulk stress divergence $u_{*}^{2} / h$ is estimated to be $f u_{*} / C$ and thus increases linearly with increasing $u *$.

Because we do not have systematic observations of $h$, Eqs. (10) and (11) cannot be evaluated from our observations. The above exercise is a nonresult but outlines the difficulty of parameterizing the stress divergence based on current observations. Evaluation of these relationships requires more complete information on the vertical structure of the flow across the boundary layer and information on the horizontal pressure gradient. For example, a lidar at an offshore flux tower and a network of meteorological stations with accurate pressure measurements would provide for better assessment of Eq. (10).

\section{Dependence on wind speed}

\section{a. Friction velocity $u_{*}$}

The dependence of $u_{*}$ on $U$ (Fig. 4a) follows a "hockey stick" dependence (Sun et al. 2012; Edson et al. 2013; Sun and French 2016), where $u *$ increases only slowly with increasing $U$, or not at all, until $U$ exceeds a threshold value of about $2-6 \mathrm{~m} \mathrm{~s}^{-1}$, depending on the site.

The averaged friction velocity $\left[u_{*}\right]$ is significant for small $U$, partly due to the contribution of random-like variations of $\overline{w^{\prime} u^{\prime}}$ to the computed $u *$. Although this averaging difficulty seems to be generally known, we provide a specific demonstration by decomposing the momentum flux $\overline{w^{\prime} u^{\prime}}$ into a systematic part, $\left[\overline{w^{\prime} u^{\prime}}\right]$ (such as bin averages), and a deviation part, $\overline{w^{\prime} u_{\mathrm{dev}}^{\prime}} \equiv$ $\overline{w^{\prime} u^{\prime}}-\left[\overline{w^{\prime} u^{\prime}}\right]$. Then $u *$ can be written as
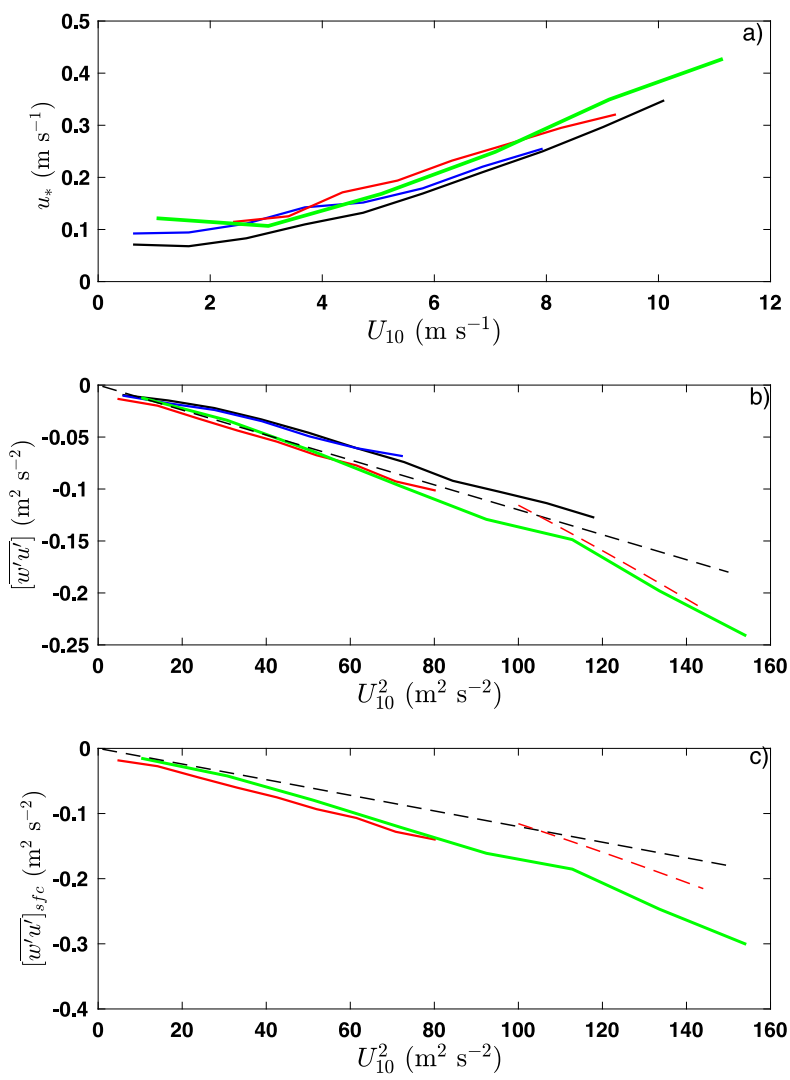

FIG. 4. (a) $\left[u_{*}\right]$ as a function of $U_{10}$ and (b) $\left[\overline{w^{\prime} u^{\prime}}\right]$ as a function of $\left[U_{10}^{2}\right]$ for the ASIT stable class (black), the ASIT unstable class (blue), the RED unstable class (red), and the MBL measurements (green). (c) $\left[\overline{w^{\prime} u^{\prime}}\right]$ adjusted for flux divergence. The formulation $\left[\overline{w^{\prime} u^{\prime}}\right]=0.0012\left[U_{10}^{2}\right]$ is the black dashed line while the modification due to Edson et al. (2013) is shown with the red dashed line.

$u_{*}=\left\{\left(\left[\overline{w^{\prime} u^{\prime}}\right]+\overline{w^{\prime} u_{\mathrm{dev}}^{\prime}}\right)^{2}+\left(\left[\overline{w^{\prime} v^{\prime}}\right]+\overline{w^{\prime} v_{\mathrm{dev}}^{\prime}}\right)^{2}\right\}^{0.25}$.

In those studies where the coordinate system is rotated into wind direction for every flux window and the crosswind stress is neglected, the two terms involving $\overline{w^{\prime} v^{\prime}}$ vanish. Expanding, Eq. (12) can be written as

$$
\begin{aligned}
u_{*}= & \left\{\left[\overline{\bar{w}^{\prime} u^{\prime}}\right]^{2}+\left(\overline{w^{\prime} u_{\mathrm{dev}}^{\prime}}\right)^{2}+2\left[\overline{{w^{\prime} u^{\prime}}^{\prime}}\right] \overline{w^{\prime} u_{\mathrm{dev}}^{\prime}}\right. \\
& \left.+\left[\overline{w^{\prime} v^{\prime}}\right]^{2}+\left(\overline{w^{\prime} v_{\mathrm{dev}}^{\prime}}\right)^{2}+2\left[\overline{w^{\prime} v}\right] \overline{w^{\prime} v_{\mathrm{dev}}^{\prime}}\right\}^{0.25} .
\end{aligned}
$$

The cross terms, such as $2\left[\overline{w^{\prime} u^{\prime}}\right] \overline{w^{\prime} u_{\mathrm{dev}}^{\prime}}$, have an expected value of zero. However, the terms $\left(\overline{w^{\prime} u_{\mathrm{dev}}^{\prime}}\right)^{2}$ and $\left(\overline{w^{\prime} v_{\text {dev }}^{\prime}}\right)$ are always positive and always augment the value of $\left[u_{*}\right]$. This augmentation is nonzero as the wind speed vanishes and is an error if $\left[u_{*}\right]$ is considered to be a measure of the systematic momentum flux. 


\section{b. Momentum flux $\left[\overline{w^{\prime} u^{\prime}}\right]$}

In contrast to $[u *]$, the momentum flux $\left[\overline{w^{\prime} u^{\prime}}\right]$ asymptotes to near zero as $U \rightarrow 0$ (Fig. 4b), at least within the uncertainty of $\left[\overline{w^{\prime} u^{\prime}}\right]$. The black dashed line in Fig. $4 \mathrm{~b}$ corresponds to $C_{d}=0.0012$, which appears to be an acceptable approximation for $U<10 \mathrm{~m} \mathrm{~s}^{-1}$, as found in Liu et al. (1979), Large and Pond (1982), and others, sometimes in the form $u *=0.035 U$. For a given field program, the slope of the dependence of $\left[\overline{w^{\prime} u^{\prime}}\right]$ on $U^{2}$ tends to increase with increasing $U^{2}$, which corresponds to the commonly observed increase of the drag coefficient with increasing $U$. The model of Edson et al. (2013) corresponds to $C_{d}=0.0012$ for low wind speeds up to $8.5 \mathrm{~m} \mathrm{~s}^{-1}$ and then follows the rough flow formulation for moderate and high winds $>8.5 \mathrm{~m} \mathrm{~s}^{-1}$ (red dashed line in Fig. 4b). The model of Andreas et al. (2012) is essentially the same except that the transition velocity is $6.0 \mathrm{~m} \mathrm{~s}^{-1}$ instead of $8.5 \mathrm{~m} \mathrm{~s}^{-1}$.

Figure $4 c$ uses the surface stress that is "corrected" for the stress divergence based on Eq. (7) and values of the depth scale $h_{S}$ from Table 1 . The shape of the dependence of the stress on $U_{10}^{2}$ [Eq. (8)] is not affected by the correction because the simplified fractional correction is independent of the wind speed. The adjustment of the surface stress (Fig. 4c) disturbs the very good agreement between the model predictions and the observed stress. One could argue that the calibration of previous models underestimates the surface stress because of the failure to correct for the stress divergence. Alternatively, the stress divergence might be at least partly due to unknown observational difficulties, or our estimated flux divergence is influenced by special physics of our datasets. In either case, more investigation is required.

\section{c. High wind}

We now consider three additional datasets that extend to relatively high wind speeds. We do not attempt correction for the stress divergence because these datasets include only one flux level. The model of Edson et al. (2013) (red dashed, Fig. 5) produces excellent agreement with the high-wind measurements using observations from less than $10 \mathrm{~m}$ above the sea surface. Measurements of stress divergence should be made at higher winds to investigate the potential impact on the inferred surface stress.

\section{Conclusions}

The dependence of $\overline{w^{\prime} u^{\prime}}$ on $U^{2}$ in our datasets is generally well predicted by existing formulations. A more general problem arises from the vertical divergence of

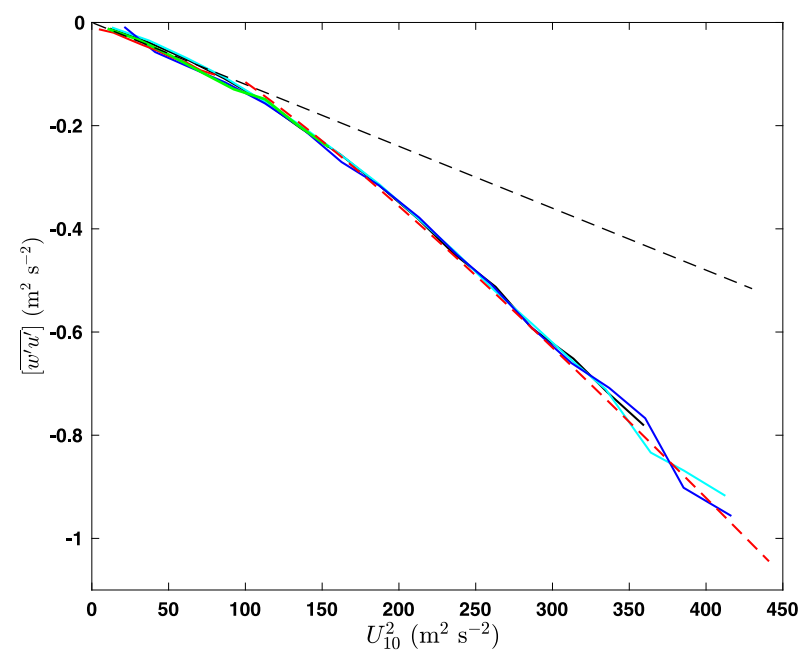

FIG. 5. The dependence of $\left[\overline{w^{\prime} u^{\prime}}\right]=0.0012$ on $\left[U_{10}^{2}\right]$ for the UNH (black) CLIMODE (cyan), ASIS (blue), RED (red), and MBL (green) measurements. The formulation $\left[\overline{w^{\prime} u^{\prime}}\right]=0.0012\left[U_{10}^{2}\right]$ is the black dashed line while the modification due to Edson et al. (2013) is the red dashed line.

the momentum flux near the surface that potentially leads to significant underestimation of the surface stress using measurements at typical observation heights. For our contrasting datasets, the surface stress was "corrected" using flux measurements at multiple levels and linear extrapolation of the momentum flux to the surface. This adjustment increases the surface stress and drag coefficient for measurements at the $10-\mathrm{m}$ level by $20 \%$ or more, depending on the field program (Table 1 ). The vertical scale implied by this flux divergence is typically $50 \mathrm{~m}$, possibly well below the top of the turbulent boundary layer. It is not known if the magnitude of the stress divergence decreases significantly with height because rigorous examination of this possibility would require multiple flux levels close to the surface and vertical structure of the entire boundary layer for a sufficiently large dataset. Aircraft observations can be used to estimate the boundary layer depth, but the lowest aircraft flux levels are generally $30 \mathrm{~m}$ or higher and can lead to serious underestimation of the surface stress.

Although our assessment of the stress divergence is based on several different field programs, the accuracy of the stress divergence and the generality of such results are not known. For example, the formulation for the stress divergence, on average, does not apply to the coastal zone measurements from ASIT where the influences of thin internal boundary layers and advection of turbulence at higher levels compete. Large datasets with both flux measurements as close as possible to the sea surface and measurements of boundary layer structure are required to sort out the influences of 
wave state, stratification, entrainment, and the heightdependent horizontal pressure gradient on the vertical divergence of the stress. See the end of section 3 for additional observational needs.

Acknowledgments. The very helpful comments of the two reviewers are gratefully acknowledged. This work was supported by the U.S. Office of Naval Research through Award N00014-16-1-2600. We thank Doug Vandemark at the University of New Hampshire for the use of his buoy data.

\section{REFERENCES}

Anderson, K., and Coauthors, 2004: The RED Experiment: An assessment of boundary layer effects in a trade winds regime on microwave and infrared propagation over the sea. Bull. Amer. Meteor. Soc., 85, 1355-1365, https://doi.org/10.1175/ BAMS-85-9-1355.

Andreas, E. L., L. Mahrt, and D. Vickers, 2012: A new drag relation for aerodynamically rough flow over the ocean. J. Atmos. Sci., 69, 2520-2537, https://doi.org/10.1175/JAS-D11-0312.1.

Edson, J. B., A. A. Hinton, K. E. Prada, J. Hare, and C. Fairall, 1998: Direct covariance flux estimates from mobile platforms at sea. J. Atmos. Oceanic Technol., 15, 547-562, https://doi.org/ 10.1175/1520-0426(1998)015<0547:DCFEFM>2.0.CO;2.

— Sea Transfer Experiment in low winds. Bull. Amer. Meteor. Soc., 88, 341-356, https://doi.org/10.1175/BAMS-88-3-341.

_ the open ocean. J. Phys. Oceanogr., 43, 1589-1610, https:// doi.org/10.1175/JPO-D-12-0173.1.

Fairall, C. W., and Coauthors, 2006: Turbulent bulk transfer coefficients and ozone deposition velocity in the International Consortium for Atmospheric Research into Transport and Transformation. J. Geophys. Res., 111, D23S20, https:// doi.org/10.1029/2006JD007597.

Flügge, M., M. M. B. Paskyabi, J. Reuder, J. B. Edson, and A. J. Plueddemann, 2016: Comparison of direct covariance flux measurements from an offshore tower and a buoy. J. Atmos. Oceanic Technol., 33, 873-890, https://doi.org/ 10.1175/JTECH-D-15-0109.1.

Foreman, R. J., and S. Emeis, 2010: Revisiting the definition of the drag coefficient in the marine atmospheric boundary layer. J. Phys. Oceanogr., 40, 2325-2332, https://doi.org/10.1175/ 2010JPO4420.1.

Garratt, J. R., 1994: The Atmospheric Boundary Layer. Cambridge University Press, 316 pp.

Geernaert, G. L., F. Hansen, and M. Courtney, 1993: Directional attributes of the ocean surface wind vector. J. Geophys. Res., 98, 16 571-16 582, https://doi.org/10.1029/93JC01439.

Grachev, A., and C. Fairall, 2001: Upward momentum transfer in the marine boundary layer. J. Phys. Oceanogr., 31, 1698-1711, https://doi.org/10.1175/1520-0485(2001)031<1698: UMTITM $>2.0 . \mathrm{CO} ; 2$.

-, C. W. Fairall, J. E. Hare, J. B. Edson, and S. D. Miller, 2003: Wind stress vector over ocean waves. J. Phys. Oceanogr., 33, 2408-2429, https://doi.org/10.1175/1520-0485(2003)033<2408: WSVOOW $>2.0 . \mathrm{CO} ; 2$.
Högström, U., A. Rutgersson, E. Sahlée, A.-S. Smedman, T. S. Hristov, W. M. Drennan, and K. K. Kahma, 2013: Air-sea interaction features in the Baltic Sea and at a Pacific tradewind site: An inter-comparison study. Bound.-Layer Meteor. 147, 139-163, https://doi.org/10.1007/s10546-012-9776-8.

Hristov, T., S. D. Miller, and C. A. Friehe, 2003: Dynamical coupling of wind and ocean waves through wave-induced air flow. Nature, 422, 55-58, https://doi.org/10.1038/nature01382.

Large, W., and S. Pond, 1982: Sensible and latent heat flux measurements over the ocean. J. Phys. Oceanogr., 12, 464-482, https:// doi.org/10.1175/1520-0485(1982)012<0464:SALHFM>2.0.CO;2.

Liu, W., K. Katsaros, and J. Businger, 1979: Bulk parameterization of air-sea exchanges of heat and water vapor including molecular constraints at the surface. J. Atmos. Sci., 36, 1722-1735, https://doi.org/10.1175/1520-0469(1979)036<1722: BPOASE $>2.0 . \mathrm{CO} ; 2$.

Mahrt, L., and C. K. Thomas, 2016: Surface stress with nonstationary weak winds and stable stratification. Bound.-Layer Meteor., 159, 3-21, https://doi.org/10.1007/s10546-015-0111-z.

_ , and T. Hristov, 2017: Is the influence of stability on the sea surface heat flux important? J. Phys. Oceanogr., 47, 689-699, https://doi.org/10.1175/JPO-D-16-0228.1.

— D. Vickers, J. Edson, J. Wilczak, J. Hare, and J. Højstrup, 2001: Vertical structure of turbulence in offshore flow during RASEX. Bound.-Layer Meteor., 100, 47-61, https://doi.org/ 10.1023/A:1018982828967.

- - E. E. L Andreas, J. B. Edson, D. Vickers, J. Sun, and E. G. Patton, 2016: Coastal zone surface stress with stable stratification. J. Phys. Oceanogr., 46, 95-105, https://doi.org/ 10.1175/JPO-D-15-0116.1.

Marshall, J., and Coauthors, 2009: The Climode Field Campaign: Observing the cycle of convection and restratification over the Gulf Stream. Bull. Amer. Meteor. Soc., 90, 1337-1350, https:// doi.org/10.1175/2009BAMS2706.1.

Miller, S., 1998: The structure of turbulent and wave-induced wind fields over open-ocean waves. Ph.D. thesis, University of California, Irvine, $202 \mathrm{pp}$.

— , T. Hristov, and J. Edson, 2008: Platform motion effects on measurements of turbulence and air-sea exchange over the open ocean. J. Atmos. Oceanic Technol., 25, 1683-1694, https://doi.org/10.1175/2008JTECHO547.1.

Oost, W. A., K. J. Komen, C. M. J. Jacobs, and C. van Oort, 2002: New evidence for a relationship between wind stress and wave age form measurements during ASGAMAGE. Bound.-Layer Meteor., 103, 409-438, https://doi.org/10.1023/A:1014913624535.

Rieder, K. F., and J. A. Smith, 1998: Removing wave effects from the wind stress vector. J. Geophys. Res., 103, 1363-1374, https://doi.org/10.1029/97JC02571.

—_ _ _ , and R. A. Weller, 1994: Observed directional characteristics of the wind, wind stress, and surface waves on the open ocean. J. Geophys. Res., 99, 22 589-22 596, https:// doi.org/10.1029/94JC02215.

Skyllingstad, E. D., R. M. Samelson, L. Mahrt, and P. Barbour, 2005: A numerical modeling study of warm offshore flow over cool water. Mon. Wea. Rev., 133, 345-361, https://doi.org/ 10.1175/MWR-2845.1.

Smedman, A.-S., U. Högström, E. Sahlée, W. M. Drennan, K. K. Kaham, and H. Pettersson, 2009: Observational study of marine atmospheric boundary layer characteristics during swell. J. Atmos. Sci., 66, 2747-2763, https://doi.org/10.1175/ 2009JAS2952.1.

Ström, L., and M. Tjernström, 2004: Variability in the summertime coastal marine atmospheric boundary-layer off California, 
USA. Quart. J. Roy. Meteor. Soc., 130, 423-448, https://doi.org/ 10.1256/qj.03.12.

Sun, J., and J. R. French, 2016: Air-sea interactions in light of new understanding of air-land interactions. J. Atmos. Sci., $\mathbf{7 3}$, 3931-3949, https://doi.org/10.1175/JAS-D-15-0354.1.

_ L. Mahrt, R. M. Banta, and Y. L. Pichugina, 2012: Turbulence regimes and turbulence intermittency in the stable boundary layer during CASES-99. J. Atmos. Sci., 69, 338-351, https:// doi.org/10.1175/JAS-D-11-082.1.
Vickers, D., L. Mahrt, and E. L. Andreas, 2015: Formulation of the sea surface friction velocity in terms of the mean wind and bulk stability. J. Appl. Meteor. Climatol., 54, 691-703, https:// doi.org/10.1175/JAMC-D-14-0099.1.

Zou, Z., D. Zhao, B. Liu, J. Zhang, and J. Huange, 2017: Observation-based parameterization of air-sea fluxes in terms of wind speed and atmospheric stability under low to moderate wind conditions. J. Geophys. Res. Oceans, 122, 4123-4142, https://doi.org/10.1002/2016JC012399. 